\title{
Chinese Urologists' Views of Practice Patterns in the Diagnosis and Treatment of Benign Prostatic Hyperplasia: A Nationwide Survey
}

\author{
Nan $\mathrm{Wu}^{1,2}$, Jian Sun ${ }^{1}$, Pulin $\mathrm{Yu}^{3}$, Zhenqiu Sun ${ }^{2}$ \\ ${ }^{1}$ Shenzhen NanShan Centre for Disease Control and Prevention, Shenzhen; \\ ${ }^{2}$ Department of Epidemiology and Statistics, School of Public health, Central South University, Changsha; \\ ${ }^{3}$ Beijing Institute of Geriatrics, Beijing Hospital, Ministry of Health, Beijing, China
}

\begin{abstract}
Purpose: To assess the compliance of Chinese urologists with China's benign prostatic hyperplasia (BPH) clinical practice guideline and to explore the diagnosis and therapy modalities for geriatric patients with $\mathrm{BPH}$.

Methods: A cross-sectional survey study was carried out in 33 medical centers in 11 different cities in China. A total of 190 urologists participated in a survey to record their preferences for diagnostic tests and treatment options for BPH outpatients. Diagnostic test results as well as health care demands were collected by surveying 2,027 outpatients aged 60 years and older.

Results: The survey response rate was $97.4 \%$. The respondents generally used the diagnostic tests recommended in China's $\mathrm{BPH}$ clinical practice guideline at varying rates. The used rates for medical history, ultrasonography, and urinalysis were above $90.0 \%$; that for uroflowmetry was $31.2 \%$. In addition, the rate of use of recommended tests was higher among doctors in the north than among those in the south. Combination therapy with $\alpha$-adrenoceptor antagonists and $5 a$-reductase inhibitors was the preferred treatment option for $\mathrm{BPH}$, and was increasingly used with worsening lower urinary tract symptoms. Finasteride was the most prescribed medication (48.0\%), followed by tamsulosin (22.7\%).

Conclusions: This study assessed the preferences of urologists in the diagnosis and treatment of BPH, which will serve as an important reference for updating and improving China’s current BPH clinical practice guideline.
\end{abstract}

Keywords: Prostatic hyperplasia; Diagnosis; Practice guideline; Therapy

\section{INTRODUCTION}

Benign prostatic hyperplasia (BPH), one of the most common diseases of aging men, is associated with bothersome lower urinary tract symptoms that affect quality of life [1]. The prevalence of histopathologic BPH is age-dependent, with initial development usually after 40 years of age [2,3]. It has been reported that approximately 4.5 million visits were made to a physician's office for a primary diagnosis of BPH in 2000, with almost 8 million visits made with a primary or secondary diagnosis of $\mathrm{BPH}$; the direct cost of $\mathrm{BPH}$ treatment was estimated to be $\$ 1.1$ billion exclusive of outpatient pharmaceuticals in 2000 [4]. The huge $\mathrm{BPH}$ population and high medical cost require greater attention to appropriate management of $\mathrm{BPH}$. Thus, it is necessary to standardize clinical practice for $\mathrm{BPH}$. The first $\mathrm{BPH}$ clinical practice guideline (CPG) was produced by the Agency for Health Care Policy and the American Urological Association in 1994 [5]. Urological Associations in Europe, Australia, and Japan subsequently issued their own BPH CPGs, which are periodically updated.

Chinas first BPH CPG was drafted in 2006 and was approved by the China Urological Association in 2007. The present study
Corresponding author: Nan Wu

Shenzhen NanShan Centre for Disease Control and Prevention, Nanshang road 95, Shenzhen, China

Tel: +86-731-84805268 / Fax: +86-731-84805268 / E-mail: wnwunan@163.com Submitted: September 17, 2012 / Accepted after revision: December 5, 2012
This is an Open Access article distributed under the terms of the Creative Commons Attribution Non-Commercial License (http://creativecommons.org/licenses/by-nc/3.0/) which permits unrestricted non-commercial use, distribution, and reproduction in any medium, provided the original work is properly cited. 
investigated the compliance of urologists with China's BPH CPG and explored the diagnostic and treatment modalities for geriatric patients with $\mathrm{BPH}$. This was the first multi-center epidemiological investigation into how China's BPH CPG is implemented in domestic clinical practice.

\section{MATERIALS AND METHODS}

\section{Participants}

This multi-center, cross-sectional survey study was undertaken in 2011 throughout China by use of stratified random sampling. The primary sampling units were cities: 11 cities were selected in north (Lanzhong, Beijing, Shenyang, and Jinan) and south (Chendu, Guangzhou, Changsha, Wuhan, Hangzhou, Nanjing, and Shanghai) China. The secondary sampling units were medical centers: 3 medical centers were randomly selected in each city, resulting in a total of 33 centers. The final sampling units were subjects, including doctors and patients selected from the outpatient department at each medical center during the study period.

Among 190 urologists from the 33 participating medical centers, 185 doctors completed the survey. The patient sample size was determined according to the $95 \%$ confidence interval. A total of 2,027 outpatients aged $\geq 60$ years with a clinical diagnosis of $\mathrm{BPH}$ (prostate size greater than $20 \mathrm{~mL}$ and a maximum flow rate less than $15 \mathrm{~mL} / \mathrm{sec}$ ) were enrolled at random. Patients with any other diseases (including severe heart disease, renal disease, neurological disease, urinary tract infection, or previous transurethral surgery) that were likely to affect urinary symptoms were excluded from the study.

\section{Methods}

The survey contained 2 sections. Section I assessed the doctors' preferences in recommended diagnostic tests, including medical history, International Prostate Symptom Score (IPSS), quality of life index, digital rectal examination, partial nervous system examination, urinalysis, prostate-specific antigen (PSA), ultrasonography, and uroflowmetry. Section II assessed the doctors' preferences in treatment on the basis of the patient's diagnosis.

Table 1. The proportion of benign prostatic hyperplasia (BPH) in male outpatients in China $(\mathrm{n}=31,371)$

\begin{tabular}{lc}
\hline Male outpatients & No. (\%) \\
\hline BPH & $14,748(47.0)$ \\
Not BPH & $16,623(53.0)$ \\
\hline
\end{tabular}

\section{Statistical Analysis}

The database was managed with Epidata 3.0 and the statistical analyses were performed with SAS 9.1 (SAS Institute Inc, Cary, NC, USA).

\section{RESULTS}

\section{Proportion of BPH in Male Outpatients}

In this study, 14,748 (47\%) of 31,371 geriatric male patients visiting an outpatient department had BPH (Table 1).

\section{Objective Parameters of the Patients}

Among the 2,027 participating outpatients, the mean age, prostate volume, peak flow rate, and quality of life index were 75.7 years, $41.8 \mathrm{~mL}, 9.6 \mathrm{~mL} / \mathrm{sec}$, and 2.6, respectively. For all three IPSS categories the prevalence of urinary symptoms was $28.6 \%$ for mild (IPSS, 0 to 7), 70.3\% for moderate (IPSS, 8 to 19), and $1.1 \%$ for severe (IPSS, 20 to 35 ) (Table 2).

\section{Doctors' Preferences for Diagnostic Tests}

Table 2. Objective parameters of the patients $(n=2,027)$

\begin{tabular}{lc}
\hline Parameter & Value \\
\hline Age (yr) & $75.7 \pm 6.9(60-96)$ \\
Prostate volume (mL) & $41.8 \pm 19.7(20.2-168.3)$ \\
Peak flow rate (mL/sec) & $9.6 \pm 2.7(3.9-14.9)$ \\
Quality of life & $2.6 \pm 1.2(1-6)$ \\
Severity of BPH (IPSS) & $579(28.6)$ \\
Mild (0-7) & $1,426(70.3)$ \\
Moderate (8-19) & $22(1.1)$ \\
Severe (20-35) & $1,555(76.7)$ \\
Prostate-specific antigen (ng/mL) & $472(23.3)$ \\
$<4$ & \\
$\geq 4$ & $1,978(97.6)$ \\
Partial nervous system examination & $49(2.4)$ \\
Normal & $1,875(92.5)$ \\
Abnormal & $152(7.5)$ \\
Urinalysis & \\
Normal & \\
\hline
\end{tabular}

Values are presented as mean \pm standard deviation (range) or number (\%).

$\mathrm{BPH}$, benign prostatic hyperplasia; IPSS, International Prostate Symptom Score. 
Among 190 urologists participating in the study, 185 completed the survey, resulting in a response rate of $97.4 \%$. Among the diagnostic tests recommended by the guideline, an overwhelming majority of the doctors used medical history (93.8\%), ultrasonography (92.7\%), or urinalysis (92.5\%) in 2,027 cases. PSA was used at a rate of $88.8 \%$, and uroflowmetry was the least used (31.2\%) (Table 3).

\section{Doctors' Preferences for Treatment Options}

In this study, drug therapy was the preferred treatment option for the 2,027 participating patients. The rate of drug therapy was $59.4 \%$ for mild cases. Both drug therapy and prostatic surgery were used for moderate and severe cases (Table 4).

Table 3. Doctors' preferences for diagnostic tests for BPH in China ( $\mathrm{n}=2,027)$

\begin{tabular}{lc}
\hline Diagnostic test & No. of cases (\%) \\
\hline Medical history & $1,901(93.8)$ \\
International Prostate Symptom Score & $1,192(58.8)$ \\
Quality of life & $1,261(62.2)$ \\
Digital rectal examination & $1,368(67.5)$ \\
Partial nervous system examination & $1,240(61.2)$ \\
Urinalysis & $1,875(92.5)$ \\
Prostate-specific antigen & $1,800(88.8)$ \\
Ultrasonography & $1,879(92.7)$ \\
Uroflowmetry & $632(31.2)$ \\
\hline
\end{tabular}

Table 4. Doctors' preferences for treatment options of patients $(\mathrm{n}=2,027)$ with benign prostatic hyperplasia in China

\begin{tabular}{lc}
\hline Treatment & No. (\%) \\
\hline Mild (n=483) & \\
Watchful waiting & $196(40.6)$ \\
Drug therapy & $287(59.4)$ \\
Surgery & $0(0)$ \\
Moderate $(\mathrm{n}=1,127)$ & \\
Watchful waiting & $327(29.0)$ \\
Drug therapy & $793(70.4)$ \\
Surgery & $7(0.6)$ \\
Severe $(\mathrm{n}=417)$ & \\
Watchful waiting & $56(13.4)$ \\
Drug therapy & $346(83.0)$ \\
Surgery & $15(3.6)$ \\
\hline
\end{tabular}

\section{Drugs Used for BPH}

Among 1,293 medical prescriptions, 1,869 drugs and 207 plants were used for treatment of $\mathrm{BPH}$ including combination therapy using more than 2 drugs or plant. Finasteride was the most preferred option (48.0\%), followed by tamsulosin (22.7\%) (Table 5).

The used rates for combination therapy with $\alpha$-adrenoceptor $(\alpha-A R)$ antagonist and $5 \alpha$-reductase inhibitor ( $5 \alpha-R I)$ increased with the severity of symptoms, from $34.2 \%$ for mild cases to $57.5 \%$ for severe cases. There was a significant difference in the used rates according to symptom severity $\left(\chi^{2}=51.179, \mathrm{P}<0.001\right)$ (Fig. 1).

\section{DISCUSSION}

A multinational study on community men aged between 40

Table 5. Drugs used for the treatment of benign prostatic hyperplasia in China

\begin{tabular}{lc}
\hline Drug & No. $(\%)$ \\
\hline a-Adrenoceptor antagonist & \\
Phenoxybenzamine & $2(0.1)$ \\
Doxazosin & $201(9.7)$ \\
Alfuzosin & $32(1.5)$ \\
Terazosin & $129(6.2)$ \\
Tamsulosin & $471(22.7)$ \\
Naftopidil & $6(0.3)$ \\
$5 a-$ Reductase inhibitor & \\
Finasteride & $997(48.0)$ \\
Epristeride & $31(1.5)$ \\
Plant & $207(10.0)$ \\
\hline
\end{tabular}

Total drug or plant prescriptions $(\mathrm{n}=2,076)$.

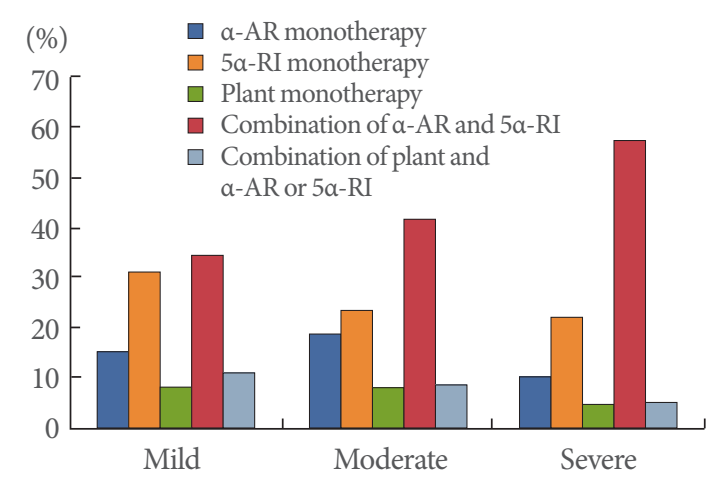

Fig. 1. Rate of use of drug therapies at different severity levels of symptoms. $\alpha$-AR, a-adrenoceptor; 5a-RI, 5a-reductase inhibitor. 
and 79 years showed that the prevalence of $\mathrm{BPH}$ was $14 \%$ in France, $18 \%$ in Scotland, 38\% in the United States, and 56\% in Japan [6]. An investigation on community-dwelling men aged 60 years and older in six cities in China in 1997 reported a 46\% prevalence of BPH [7]. In our study, approximately $50 \%$ of geriatric outpatients aged 60 years and older had BPH. Obviously, $\mathrm{BPH}$ is a common disease of elderly men in China. CPGs are believed to improve the quality of clinical decisions by helping and reassuring doctors who may be uncertain about the appropriateness of a clinical choice [8]. Thus, establishing and implementing a CPG for $\mathrm{BPH}$ is important in the management of BPH. To date, several CPGs have addressed the optimal treatment of men with BPH. In clinical areas in which there are numerous guidelines, however, there is considerable variations in the recommendations made [9]. In addition, although guidelines provide a framework for evaluation and treatment, they leave a great deal of room for the personal opinions of individual doctors. For example, digital rectal examination and PSA are recommended by most of the guidelines. However, some surveys have shown large differences in the using rates of these tests between countries [10-13]. In our study, digital rectal examination was used at a rate of $67.5 \%$, and PSA was used at a rate of $88.8 \%$. These differences may, in part, result from differences in local health service issues, such as socialized medical systems, manpower issues, availability of extensive technology, the unique perspective of local doctors, or cultural differences in urological practices.

With regard to treatment options, drug therapy was the preferred treatment option in our study. Our results indicate that doctors prefer watchful waiting for less than $50 \%$ of mild cases, which could lead to overprescription of medications for patients with mild symptoms, because watchful waiting is the recommended strategy for patients with mild $\mathrm{BPH}$. When prescribing medications for BPH, $\alpha$-AR antagonists (e.g., tamsulosin) and $5 \alpha$-RIs (e.g., finasteride) are the medications currently approved by the U.S. Food and Drug Administration for the treatment of $\mathrm{BPH}$ [14]. In our study, finasteride was the most preferred option (48.0\%), followed by tamsulosin (22.7\%). This finding is consistent with recent reports by others in China showing that finasteride held the major share of prescriptions [15]. In our study, finasteride was used more often than $\alpha$-AR antagonist therapy. This may be because in our study most patients had moderate and severe symptoms. Moreover, convincing evidence exists for the effectiveness of finasteride in the treatment of moderate and severe BPH [16-18]. This may have led the doctors in the present study to prefer finasteride for their patients. Combination therapy with $\alpha$-AR antagonist and $5 \alpha-R I$ was used more often for patients with severe symptoms, which is consistent with the findings of other studies [19-22].

In conclusion, this is the first multi-center epidemiological study to quantify the extent to which China's BPH CPG is implemented in clinical practice. This study assessed the preferences of urologists in the diagnosis and treatment of $\mathrm{BPH}$, which will serve as an important reference for updating and improving China's current BPH CPG.

\section{CONFLICT OF INTEREST}

No potential conflict of interest relevant to this article was reported.

\section{REFERENCES}

1. Roehrborn CG, McConnell JD. Etiology, pathophysiology, epidemiology and natural history of benign prostatic hyperplasia. In: Walsh PC, Retik AB, Vaughan ED Jr, Wein AJ, Kavoussi LR, Novick AC, et al., editors. Campbell's urology. 8th ed. Philadelphia: WB Saunders; 2002. p. 1297-336.

2. Berry SJ, Coffey DS, Walsh PC, Ewing LL. The development of human benign prostatic hyperplasia with age. J Urol 1984;132:474-9.

3. Gu FL, Xia TL, Kong XT. Preliminary study of the frequency of benign prostatic hyperplasia and prostatic cancer in China. Urology 1994;44:688-91.

4. Wei JT, Calhoun E, Jacobsen SJ. Urologic diseases in America project: benign prostatic hyperplasia. J Urol 2005;173:1256-61.

5. McConnell JD, Barry MJ, Bruskewitz RC, Bueschen AJ, Denton SE, Holtgrewe HL, et al. Benign prostatic hyperplasia: diagnosis and treatment (Clinical practice guideline no. 8; AHCPR publication no. 94-0582). Rockville: U.S. Department of Health and Human Services, Agency for Healthcare Research and Quality; 1994.

6. Sagnier PP, Girman CJ, Garraway M, Kumamoto Y, Lieber MM, Richard F, et al. International comparison of the community prevalence of symptoms of prostatism in four countries. Eur Urol 1996; 29:15-20.

7. Yu P, Zheng H, Su H, Zuo T, Duan C, Gao F, et al. Prevalence of prostatic hyperplasia and its relative factors in six cities of China in 1997. Zhonghua Liu Xing Bing Xue Za Zhi 2000;21:276-9.

8. Gravas S, Tzortzis V, Melekos MD. Translation of benign prostatic hyperplasia guidelines into clinical practice. Curr Opin Urol 2008; 18:56-60. 
9. Irani J, Brown CT, van der Meulen J, Emberton M. A review of guidelines on benign prostatic hyperplasia and lower urinary tract symptoms: are all guidelines the same? BJU Int 2003;92:937-42.

10. Kim HL, Benson DA, Stern SD, Gerber GS. Practice trends in the management of prostate disease by family practice physicians and general internists: an internet-based survey. Urology 2002;59:26671.

11. Fukagai T, Maruyama K, Nagata M, Morita M, Naoe M, Yoshida H. Practice patterns regarding prostate cancer and benign prostatic hyperplasia in Japanese primary care practitioners. Int J Urol 2007; 14:412-5.

12. Hutchison A, Farmer R, Chapple C, Berges R, Pientka L, Teillac P, et al. Characteristics of patients presenting with LUTS/BPH in six European countries. Eur Urol 2006;50:555-61.

13. Paick JS, Kim SW, Ku JH. Patterns in the diagnosis and management of benign prostatic hyperplasia in a country that does not have country-specific clinical practice guidelines. Yonsei Med J 2007;48: 281-8.

14. Physicians' desk reference. 61st ed. Montvale: Thomson PDR; 2007.

15. Lin T. Market analysis of medicines for treatment of benign prostatic hyperplasia in sample hospitals of Shanghai. Pharm Care Res 2006;6:370-2.

16. Bruskewitz R, Girman CJ, Fowler J, Rigby OF, Sullivan M, Bracken $\mathrm{RB}$, et al. Effect of finasteride on bother and other health-related quality of life aspects associated with benign prostatic hyperplasia. PLESS Study Group. Proscar Long-term Efficacy and Safety Study. Urology 1999;54:670-8.
17. Kaplan SA, Lee JY, Meehan AG, Kusek JW; MTOPS Research Group. Long-term treatment with finasteride improves clinical progression of benign prostatic hyperplasia in men with an enlarged versus a smaller prostate: data from the MTOPS trial. J Urol 2011;185:136973.

18. Vickers AJ, Savage CJ, Lilja H. Finasteride to prevent prostate cancer: should all men or only a high-risk subgroup be treated? J Clin Oncol 2010;28:1112-6.

19. Speakman MJ. Integrating patient risk profiles in the treatment of lower urinary tract symptoms suggestive of benign prostatic hyperplasia (LUTS/BPH) in Clinical Practice. Eur Urol Suppl 2004;3:1822.

20. McConnell JD, Roehrborn CG, Bautista OM, Andriole GL Jr, Dixon CM, Kusek JW, et al. The long-term effect of doxazosin, finasteride, and combination therapy on the clinical progression of benign prostatic hyperplasia. N Engl J Med 2003;349:2387-98.

21. Kaplan SA, McConnell JD, Roehrborn CG, Meehan AG, Lee MW, Noble WR, et al. Combination therapy with doxazosin and finasteride for benign prostatic hyperplasia in patients with lower urinary tract symptoms and a baseline total prostate volume of $25 \mathrm{ml}$ or greater. J Urol 2006;175:217-20.

22. Lee JY, Lee SH, Kim SJ, Kim CS, Lee HM, Kim CI, et al. Change in International Prostate Symptom storage subscore after long-term medical therapy in $\mathrm{BPH}$ patients: finasteride and alpha-blocker combination therapy in men with moderate-to-severe LUTS/BPH in Korea. Urology 2011;77:171-6. 